\title{
Ruptured Small Intestinal Stromal Tumor Causing Concurrent Gastrointestinal and Intra-Abdominal Hemorrhage: A Case Report
}

\author{
Yoichiro Tada,* Manabu Yamamoto,* Shohei Sawata,* Kazushi Hara,* Ken Sugesawa,* Chihiro Ueshima," \\ Akimitsu Tanio,* Kyoichi Kihara,* Tomoyuki Matsunaga,* Naruo Tokuyasu,* Shuichi Takano,* Teruhisa Sakamoto,* \\ Soichiro Honjo,* Toshimichi Hasegawa* and Yoshiyuki Fujiwara* \\ *Division of Gastrointestinal and Pediatric Surgery, Department of Surgery, School of Medicine, Faculty of Medicine, Tottori \\ University, Yonago 683-8504, Japan
}

\begin{abstract}
Gastrointestinal stromal tumors (GISTs) originate from mesenchymal cells throughout the gastrointestinal tract. A common symptom is gastrointestinal hemorrhage; intra-abdominal hemorrhage is relatively rare. There are few reports of GIST presenting with both types of hemorrhage concurrently. A 77-year-old man was admitted to our hospital because of melena and anemia ( $\mathrm{Hb}: 4.7$ $\mathrm{g} / \mathrm{dL}$ ). Computed tomography revealed a small bowel tumor and high-density fluid in both the small intestine and the pelvic floor. We diagnosed a small intestinal tumor with concurrent gastrointestinal and intraabdominal hemorrhage, and performed emergency surgery. The tumor arose from the small intestine and was ruptured. We found hemorrhage in the pelvic cavity and performed partial small intestine resection. Pathological findings revealed that the tumor was positive for $\mathrm{c}$ Kit protein and was diagnosed as GIST. The patient was discharged from the hospital on postoperative day 9 and received imatinib 1 month postoperatively. We experienced a very rare case of ruptured GIST originating from the small intestine associated with both gastrointestinal and intra-abdominal hemorrhage. We also reviewed the relevant literature.
\end{abstract}

Key words gastrointestinal hemorrhage; gastrointestinal stromal tumor; intra-abdominal hemorrhage; rupture; small intestine

Gastrointestinal stromal tumors (GISTs) arise from mesenchymal cells in the stomach $(50 \%-60 \%)$, small intestine $(30 \%-35 \%)$, rectum $(5 \%)$, and esophagus $(<1 \%) .{ }^{1}$ The occurrence rate has been estimated at approximately $10-20$ per 1 million people. ${ }^{2-6}$ The majority of GISTs are asymptomatic, and symptomatic GISTs usually have a certain degree of size. Previous

Corresponding author: Manabu Yamamoto, MD, PhD

m.yamamoto@tottori-u.ac.jp

Received 2021 January 21

Accepted 2021 February 12

Online published 2021 February 22

Abbreviation: GIST, gastrointestinal stromal tumor reports revealed that GISTs $>5 \mathrm{~cm}$ in diameter had a risk of rupture, and that two-thirds of GISTs originating from the small intestine were $>5 \mathrm{~cm}$ in diameter at diagnosis. $^{7}$

The common presentations of GISTs are abdominal pain, nausea, vomiting, and gastrointestinal hemorrhage. The most common symptom is gastrointestinal hemorrhage, and intra-abdominal hemorrhage is very rare. If these hemorrhage events occur simultaneously, they may be life-threatening, and emergency intervention such as surgery or catheter embolization may be necessary.

We found only two reports of GIST describing both types of hemorrhage concurrently ${ }^{8,9}$ (Table 1). We report a patient with a small intestinal GIST presenting with both gastrointestinal and intra-abdominal hemorrhage that was successfully treated surgically.

\section{PATIENT REPORT}

A 77-year-old man visited a nearby hospital for melena and laboratory data showed a decreased hemoglobin level of $8.5 \mathrm{~g} / \mathrm{dL}$. His vital signs were normal, and a lower gastrointestinal endoscopy was scheduled on a standby basis. However, because of persistent melena, he returned to the hospital two days later. By then, the anemia was more advanced $(4.7 \mathrm{~g} / \mathrm{dL})$ and he was referred to our hospital. His blood pressure was 122/68 $\mathrm{mmHg}$, heart rate: 100 beats per minute, and body temperature: $37.5^{\circ} \mathrm{C}$. Physical examination revealed facial pallor, slight abdominal pain, and a mass in the lower mid-abdomen. He had a history of hypertension that was not successfully controlled. Laboratory data showed an increased white blood cell count of 8900 cells $/ \mu \mathrm{L}$, and an increased C-reactive protein level of $2.28 \mathrm{mg} / \mathrm{dL}$. Abdominal contrast enhanced computed tomography revealed a small intestinal tumor $(8 \mathrm{~cm}$ in diameter) and high-density fluid collections in both the small intestine (Fig. 1a) and the pelvic cavity (Fig. 1b). The tumor was entirely contrasted, however, some areas were poorly contrasted and thought to be necrotic. The fluid in the small intestine had a high contrast effect, suggesting that active bleeding was occurring. 
Table 1. Reports of patients with GIST with concurrent gastrointestinal and intra-abdominal hemorrhage

\begin{tabular}{cccccccc}
\hline Case & Author & Age & Sex & Size $(\mathrm{cm})$ & $\begin{array}{c}\text { Volume of intraabdominal } \\
\text { hemorrhage }(\mathrm{mL})\end{array}$ & Hemorrhagic shock & Emergency surgery \\
\hline 1 & Kobayashi & 44 & M & 9.5 & - & Yes & Yes \\
2 & Park & 67 & F & 3.5 & - & No & Yes \\
3 & Our case & 77 & M & 8 & 90 & No & Yes \\
\hline
\end{tabular}

F, female; M, male.
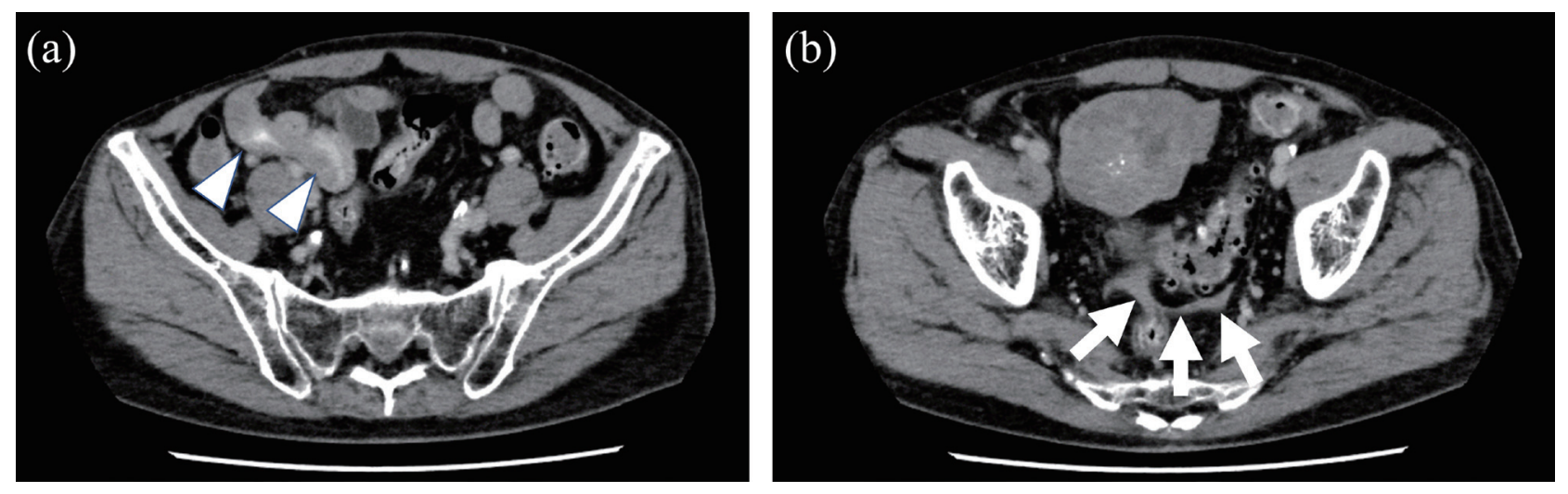

Fig. 1. High-density fluid collections in the intestine (arrow heads) (a) and pelvic cavity (arrows) (b).

We diagnosed concurrent gastrointestinal and intraabdominal hemorrhage from the small bowel tumor. Because of the marked anemia and suspected continued hemorrhage, we performed emergency laparotomy after blood transfusion.

Intraoperatively, we identified a mass in the pelvic floor, which arose from the small intestine and which was located $210 \mathrm{~cm}$ from the ileocecal area. The surface capsule was ruptured intraperitoneally, which caused persistent venous hemorrhage and intra-abdominal hemorrhage (approximately $90 \mathrm{~mL}$ ) (Fig. 2a), and we found no peritoneal dissemination or enlarged lymph nodes. We partially resected the small intestine, including the mass, and found a large amount of gastrointestinal hemorrhage in the small intestinal lumen. The operative time was 1 hour and 11 minutes, and blood loss volume was approximately $90 \mathrm{~mL}$, which was consistent with the existing intra-abdominal hemorrhage.

The tumor was round, measured $8 \mathrm{~cm}$ in diameter, protruded from the intestinal wall, and penetrated the mucosal side of the small intestine. A ruptured site was present on the intestinal mucosa and a broken vein was found in the ruptured site (Fig. $2 b$ and Fig. 3). Hematoxylin and eosin staining revealed increased numbers of spindle-shaped cells, nuclear palisading (Fig. 4a), hemorrhage, and necrosis. The mitotic count was 1 mitotic cell per $\times 50$ high-power field.
Immunohistochemical staining revealed that the tumor was positive for c-Kit (Fig. 4b) and negative for S-100 and desmin proteins. The MIB-1 index was approximately $2.4 \%$ (Fig. 4c). According to these results, we diagnosed the tumor as a small intestinal GIST. The patient's postoperative course was stable, and he was discharged from the hospital on postoperative day 9 . He began oral administration of imatinib 1 month after surgery and was free of recurrence for 3 months after surgery, at the time of this report.

\section{DISCUSSION}

GISTs originate from mesenchymal cells and account for $0.2 \%-1.0 \%$ of all gastrointestinal tumors. ${ }^{10}$ These tumors arise from any part of the gastrointestinal tract, however, the stomach is the most common primary site, and the small intestine is the second most common site.

Patients with small GISTs usually show no symptoms. However, when tumors grow, abdominal pain or gastrointestinal hemorrhage occurs. Previous reports stated that GISTs over $5 \mathrm{~cm}$ in diameter often ruptured spontaneously, and that two-thirds of small intestinal GISTs are $>5 \mathrm{~cm}$ in diameter at diagnosis and have a risk of rupture. ${ }^{7}$

Fukuda et al. reported small GISTs of $2 \mathrm{~cm}$ in diameter in the small intestine rupturing and causing hemoperitoneum. ${ }^{11}$ However, 13/15 ruptured GISTs in the 

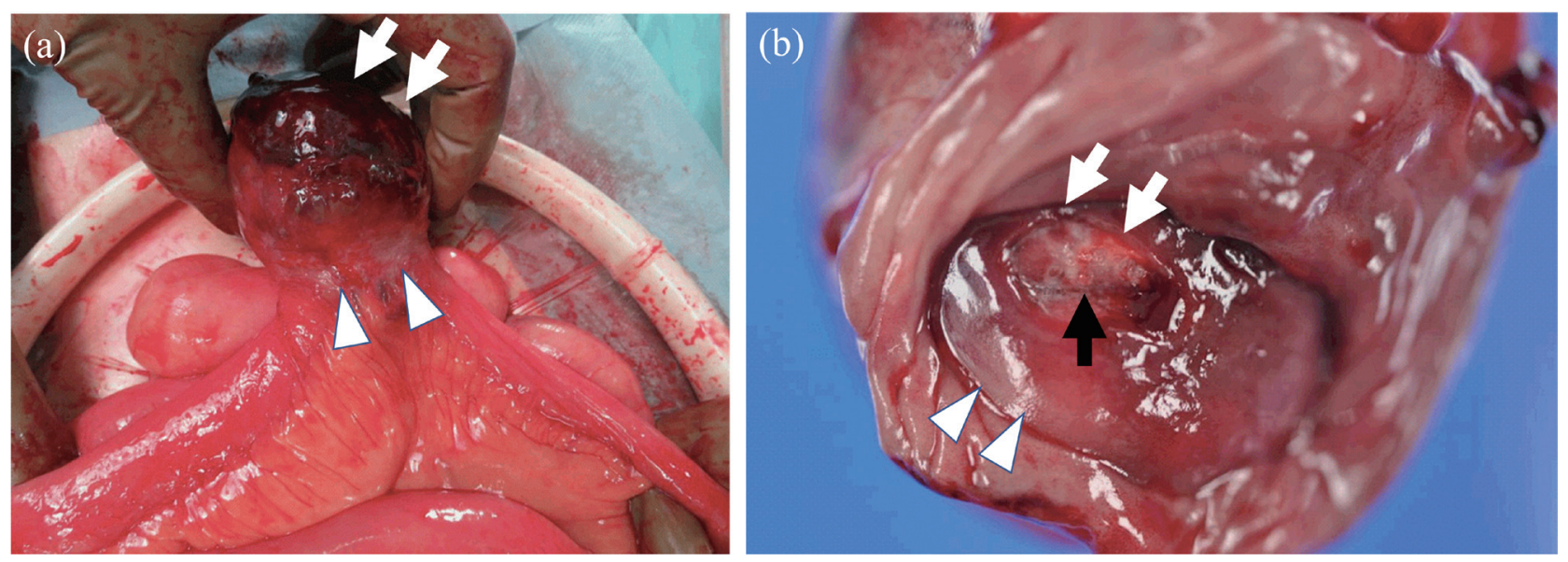

Fig. 2. (a) The tumor arose from the small intestine and protruded from the intestinal wall (arrow heads). The surface capsule of the tumor was partially ruptured (arrows), and (b) penetrated the mucosal side of the small intestine (arrow heads). The ruptured site was seen on the surface (white arrows). A broken vein was found in the ruptured site (black arrow).
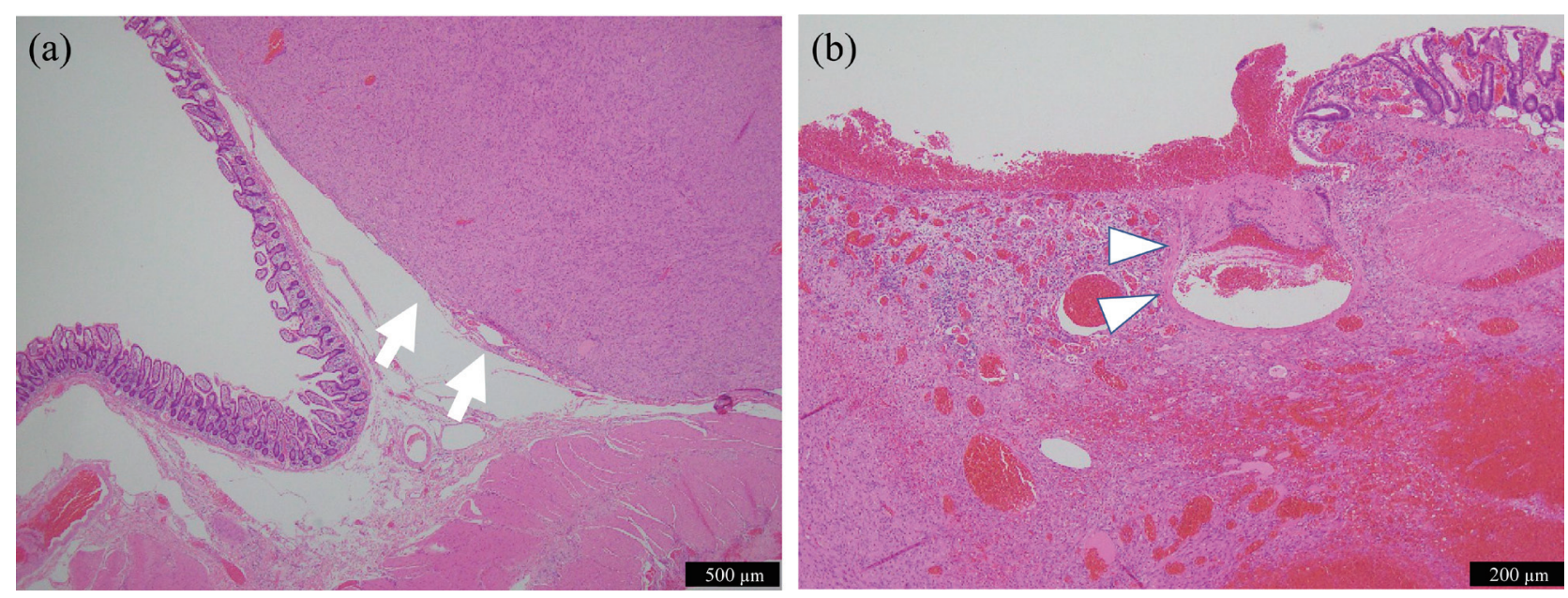

Fig. 3. (a) The tumor was located under the submucosa of the small intestine (arrows). Bar $=500 \mu \mathrm{m}$. (b) A broken vein was found in the ruptured site and covered in fibrin (arrow heads). Bar $=200 \mu \mathrm{m}$.

previous report were $>5 \mathrm{~cm}$ in size, which is associated with a potential for rupture ${ }^{8,9,11-23}$ (Table 2). Fukuda et al.'s patient with hemorrhage related to a tumor $<5$ $\mathrm{cm}$ in diameter was remarkably rare considering that tumor growth increased intratumoral pressure and led to rupture causing intra-abdominal hemorrhage. ${ }^{16,22}$

A previous report showed that ulceration was present in 343/969 patients (38\%) with GISTs, and often causes gastrointestinal bleeding from ulcers. In fact, GISTs most commonly presented with melena and abdominal pain; $18 \%$ of them were incidentally found. ${ }^{7}$ In our case, the patients had melena and rapid progression of anemia. CT scan showed high density site in the gastrointestinal tract, and also showed high density site in the pelvis. These findings were suspected as the occurrence of concurrent gastrointestinal and intra-abdominal hemorrhage. When GISTs rupture, they tend to bleed into the abdominal cavity, and the hemorrhage is likely to be persistent. This is because the intra-abdominal cavity has a large volume, and it is difficult to stop the hemorrhage. Indeed, in the previous ruptured cases, there had a large amount of bleeding in the abdominal cavity, ${ }^{11}, 12,15,16,19,21$ however, in our patient, the intra-abdominal hemorrhage volume was small and the gastrointestinal hemorrhage volume was large. Though it is certain that the hemorrhage from the vessel damaged by the rupture was predominantly into the intestinal tract through the ulcer, it is unclear why the gastrointestinal hemorrhage mainly occurred, and why both hemorrhage occurred simultaneously. 

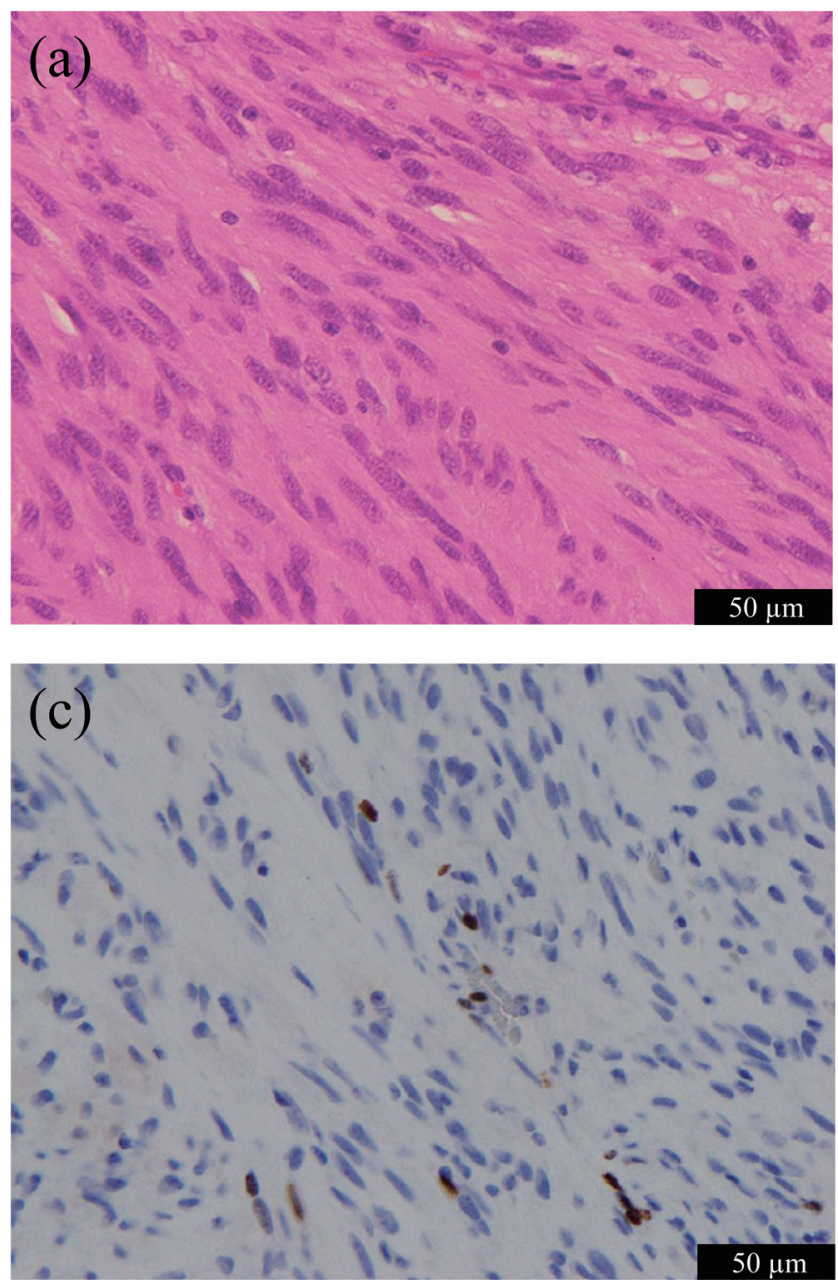

Therefore, further research is needed.

The concurrent gastrointestinal and intraabdominal hemorrhage of small intestinal GISTs are remarkably rare, with only two reports ${ }^{8,9}$ (Table 1) found in a PubMed search. Both gastrointestinal and intraabdominal hemorrhage carry a risk of hemorrhagic shock. In fact, two previous patients and our patient required emergency surgery because of the continuous hemorrhage.

We performed open surgery from the beginning because the tumor was $8 \mathrm{~cm}$ in size and needed incision over $8 \mathrm{~cm}$ to remove from the abdominal cavity and laparotomy made intra-abdominal lavage easy. Previous reports revealed that $13 / 15$ patients with ruptured small intestinal GISTs $>5 \mathrm{~cm}$ underwent laparotomy or laparoscopy converted to laparotomy, and $2 / 15<5 \mathrm{~cm}$ underwent laparoscopy, however, only one patient could accomplish laparoscopy $8,9,11-23$ (Table 2). Because the principal reason of conversion to laparotomy was a large amount of intra-abdominal hemorrhage and size $>5 \mathrm{~cm}$ is a risk of rupture, laparotomy is thought to be

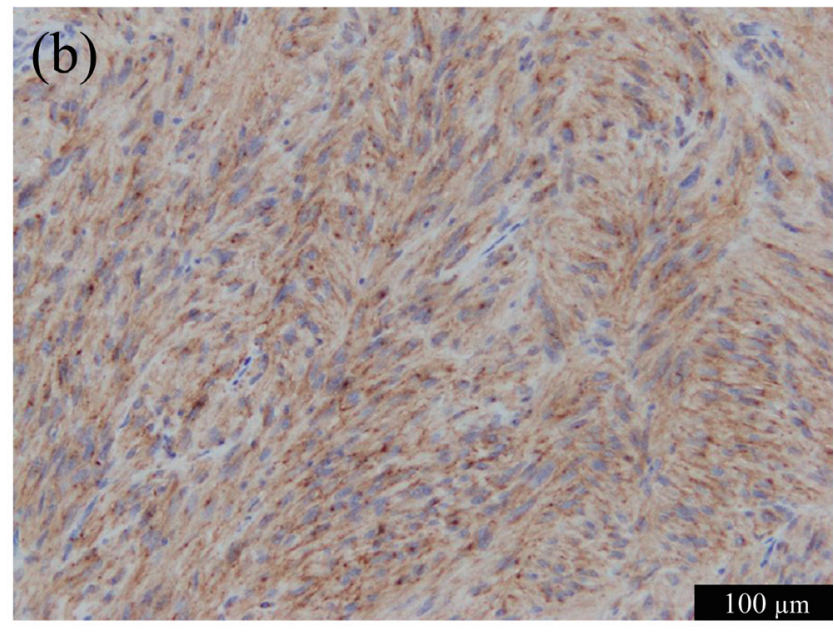

Fig. 4. (a) Increased numbers of spindle-shaped cells and nuclear palisading (hematoxylin and eosin stain). Bar $=50 \mu \mathrm{m}$. (b) The tumor was positive for c-Kit (immunohistochemical stain). Bar $=$ $100 \mu \mathrm{m}$. (c) The MIB-1 index was approximately $2.4 \%$. Bar $=50$ $\mu \mathrm{m}$.

a good operation method for GISTs $>5 \mathrm{~cm}$ with intraabdominal hemorrhage.

Though there is a report of radiological embolization, ${ }^{24}$ it is not a radical cure and it may cause intestinal necrosis. Furthermore, the tumor caused a $4-\mathrm{g} / \mathrm{dL}$ reduction in hemoglobin after 2 days, the excision of intestine is simple, and the excision combines treatment and diagnosis. Based on these reasons, we did not choose it.

The risk factors for GIST recurrence are tumor size, mitosis count, site of origin, and tumor rupture. ${ }^{1}$ The Japanese GIST guidelines ${ }^{25}$ indicate a treatment strategy based on the risk of recurrence. Our patient had a high risk of recurrence because of the tumor size and tumor rupture, according to the guidelines; therefore, we started imatinib therapy 1 month after surgery. Careful follow-up of our patient is needed.

In conclusion, few reports describe GIST presenting with concurrent gastrointestinal and intra-abdominal hemorrhage. Because this scenario potentially leads to hemorrhagic shock, careful observation and emergency 
Table 2. Reports of patients with ruptured small intestinal GISTs

\begin{tabular}{cccccccc}
\hline Case & Author & Age & Sex & $\begin{array}{c}\text { Size }(\mathrm{cm}) \\
\text { (descending order) }\end{array}$ & $\begin{array}{c}\text { Operative } \\
\text { method }\end{array}$ & $\begin{array}{c}\text { Volume of intraabdominal } \\
\text { hemorrhage }(\mathrm{mL})\end{array}$ & $\begin{array}{c}\text { Hemorrhagic } \\
\text { shock }\end{array}$ \\
\hline 1 & Iusco & 76 & M & 20 & Laparotomy & - & Yes \\
\hline 2 & Lai & 54 & M & 20 & Conversion to laparotomy & - & - \\
3 & Worley & 39 & M & 16 & - & 500 & No \\
\hline 4 & Dubenec & 48 & M & 15 & Conversion to laparotomy & 1200 & No \\
\hline 5 & Hirasaki & 87 & F & 13 & Laparotomy & - & No \\
\hline 6 & Varras & 28 & F & 13 & Laparotomy & 1000 & No \\
7 & Nannini & 45 & F & 12 & - & - & - \\
8 & Mahmoud & 87 & M & 10 & Laparotomy & - & No \\
\hline 9 & Wang & 51 & M & 10 & Laparotomy & 1600 & Yes \\
\hline 10 & Kobayashi & 44 & M & 9.5 & Laparotomy & - & Yes \\
11 & Cegarra-Navarro & 76 & M & 9 & - & - & Yes \\
\hline 12 & Attaallah & 46 & M & 8 & Laparotomy & 1000 & No \\
13 & Ajduk & 60 & F & 7.5 & Laparotomy & - & No \\
\hline 14 & Park & 67 & F & 3.5 & Laparoscopy & - & No \\
15 & Fukuda & 72 & M & 2 & Conversion to laparotomy & 1500 & No \\
\hline 16 & Our case & 77 & M & 8 & Laparotomy & 90 & No \\
\hline
\end{tabular}

F, female; M, male.

intervention, including surgery, are necessary. In the present study, successful results were obtained by emergency surgery, and the timing of surgery was considered to be appropriate.

Acknowledgments: We thank Jane Charbonneau, DVM from Edanz Group (www.edanzediting.com/ac), for editing a draft of this manuscript.

\section{The authors declare no conflict of interest.}

\section{REFERENCES}

1 Joensuu H, Vehtari A, Riihimäki J, Nishida T, Steigen SE, Brabec P, et al. Risk of recurrence of gastrointestinal stromal tumour after surgery: an analysis of pooled population-based cohorts. Lancet Oncol. 2012;13:265-74. DOI: 10.1016/S14702045(11)70299-6, PMID: 22153892

2 Lamba G, Gupta R, Lee B, Ambrale S, Liu D. Current management and prognostic features for gastrointestinal stromal tumor (GIST). Exp Hematol Oncol. 2012;1:14. DOI: 10.1186/2162-3619-1-14, PMID: 23210689

3 Lv A, Li Z, Tian X, Guan X, Zhao M, Dong B, et al. SKP2 high expression, KIT exon 11 deletions, and gastrointestinal bleeding as predictors of poor prognosis in primary gastrointestinal stromal tumors. PLoS One. 2013;8:e62951. DOI: 10.1371/journal.pone.0062951, PMID: 23690967

4 Steigen S, Eide TJ. Gastrointestinal stromal tumors (GISTs): a review. APMIS. 2009;117:73-86. DOI: 10.1111/j.16000463.2008.00020.x, PMID: 19239429
5 Miettinen M, Majidi M, Lasota J. Pathology and diagnostic criteria of gastrointestinal stromal tumors (GISTs): a review. Eur J Cancer. 2002;38:Suppl 5. PMID: 12528772

6 Xiao CC, Zhang S, Wang MH, Huang LY, Wu P, Xu Y, et al. Clinicopathological features and prognostic factors of rectal gastrointestinal stromal tumors. J Gastrointest Surg. 2013;17:793-8. DOI: 10.1007/s11605-012-2086-0, PMID: 23288714

7 Miettinen M, Makhlouf H, Sobin LH, Lasota J. Gastrointestinal stromal tumors of the jejunum and ileum: a clinicopathologic, immunohistochemical, and molecular genetic study of 906 cases before imatinib with long-term follow-up. Am J Surg Pathol. 2006;30:477-89. DOI: 10.1097/00000478200604000-00008, PMID: 16625094

8 Kobayashi H, Hirajima S, Takagi T, Fukumoto K. [A Case of Gastrointestinal Stromal Tumor of the Small Intestine Complicated by Hemorrhagic Shock Due to Gastrointestinal and Intraperitoneal Bleedings]. Gan To Kagaku Ryoho. 2017;44:1726-8. PMID: 29394756 Japanese with English abstract.

9 Park DY, Moon W. Simultaneous occurrence of obscure-overt gastrointestinal and intraperitoneal bleeding in gastrointestinal stromal tumor. Clin Gastroenterol Hepatol. 2010;8:A28. DOI: 10.1016/j.cgh.2009.04.014, PMID: 19394442

10 Crosby JA, Catton CN, Davis A, Couture J, O'Sullivan B, Kandel R, et al. Malignant gastrointestinal stromal tumors of the small intestine: a review of 50 cases from a prospective database. Ann Surg Oncol. 2001;8:50-9. DOI: 10.1007/s10434001-0050-4, PMID: 11206225 
11 Fukuda S, Fujiwara Y, Wakasa T, Inoue K, Kitani K, Ishikawa $\mathrm{H}$, et al. Small, spontaneously ruptured gastrointestinal stromal tumor in the small intestine causing hemoperitoneum: A case report. Int J Surg Case Rep. 2017;36:64-8. DOI: 10.1016/j.ijscr.2017.05.019, PMID: 28549261

12 Dubenec SR, Dawes-Higgs EK, Higgs RJED, Truskett PG. Haemoperitoneum caused by spontaneous rupture of a gastrointestinal stromal tumour. ANZ J Surg. 2001;71:612-4. DOI: 10.1046/j.1445-2197.2001.02217.x, PMID: 11552940

13 Cegarra-Navarro MF, de la Calle MAC, Girela-Baena E, García-Santos JM, Lloret-Estañ F, de Andrés EP. Ruptured gastrointestinal stromal tumors: radiologic findings in six cases. Abdom Imaging. 2005;30:535-42. DOI: 10.1007/ s00261-005-0308-6, PMID: 15834676

14 Hirasaki S, Fujita K, Matsubara M, Kanzaki H, Yamane H, Okuda $\mathrm{M}$, et al. A ruptured large extraluminal ileal gastrointestinal stromal tumor causing hemoperitoneum. World J Gastroenterol. 2008;14:2928-31. DOI: 10.3748/wjg.14.2928, PMID: 18473425

15 Wang CY, Du F, Huang SM, Tsai YC. Nontraumatic hemoperitoneum due to spontaneous gastrointestinal stromal tumor rupture: A case report. Zhonghua Fang She Xue Za Zhi. 2009;34:293-7.

16 Worley TA, Abadin SS, Revesz E, Salti GI. Gastrointestinal stromal tumor with hemoperitoneum masquerading as appendicitis. Int Surg. 2010;95:8-11. PMID: 20480834

17 Iusco D, Jannaci M, Grassi A, Bonomi S, Ismail I, Navarra G, et al. Giant ileal gastrointestinal stromal tumour presenting as an intestinal subocclusion and subsequent haemoperitoneum: a case report and a review of the literature. Updates Surg. 2010;62:189-93. DOI: 10.1007/s13304-010-0034-7, PMID: 21116885

18 Mahmoud EA, Fadhel F, Amin M, Wael R, Amin D, Haykel $\mathrm{B}$, et al. A ruptured ileal GI stromal tumor causing hemoperitoneum. Gastrointest Endosc. 2010;71:185-6. DOI: 10.1016/ j.gie.2009.08.022, PMID: 19879571
19 Varras M, Vlachakos N, Akrivis C, Vasilakaki T, Skafida E. Malignant gastrointestinal stromal tumor presenting with hemoperitoneum in puerperium: report of a case with review of the literature. World J Surg Oncol. 2010;8:95. DOI: 10.1186/1477-7819-8-95, PMID: 21054898

20 Nannini M, Pantaleo MA, Catena F, Romano S, Tondo S, Pirini MG, et al. Surgical second-look in high risk gastrointestinal stromal tumor of small intestine: A case report. Int J Surg Case Rep. 2013;4:7-10. DOI: 10.1016/j.ijscr.2012.07.019, PMID: 23088904

21 Attaallah W, Coşkun S, Özden G, Mollamemişoğlu H, Yeğen C. Spontaneous rupture of extraluminal jejunal gastrointestinal stromal tumor causing acute abdomen and hemoperitoneum. Turk J Surg. 2015;31:99-101. DOI: 10.5152/ UCD.2015.2877, PMID: 26170759

22 Lai ECH, Chung KM, Lau SHY, Lau WY. A ruptured recurrent small bowel gastrointestinal stromal tumour causing hemoperitoneum. Frontiers of Medicine. 2015;9:108-11. DOI: 10.1007/s11684-014-0344-0, PMID: 25001102

23 Ajduk M, Mikulić D, Sebecić B, Gasparov S, Patrlj L, Erdelez L, et al. Spontaneously ruptured gastrointestinal stromal tumor (GIST) of the jejunum mimicking acute appendicitis. Coll Antropol. 2004;28:937-41. PMID: 15666631

24 Koo HJ, Shin JH, Shin S, Yoon HK, Ko GY, Gwon DI. Efficacy and Clinical Outcomes of Transcatheter Arterial Embolization for Gastrointestinal Bleeding from Gastrointestinal Stromal Tumor. J Vasc Interv Radiol. 2015;26:1297-1304.el. DOI: 10.1016/j.jvir.2015.06.005, PMID: 26190186

25 Clinical Practice Guidelines for Gastrointestinal Stromal Tumor (GIST) in Japan. Tokyo: Kanehara Shuppan. 2014. Japanese. 